\title{
Report on the Technology, Mind, and Society Conference
}

- The Technology, Mind, and Society (TMS) conference was organized by the American Psychological Association and held in Washington, DC, on April 5-7, 2018. This report summarizes the conference.
Amber L. Story

$\mathrm{T}$ The Technology, Mind, and Society ${ }^{1}$ conference organized by the American Psychological Association (APA) was held in Washington, DC, April 5-7, 2018. APA welcomed scientists, practitioners, policymakers, and students from around the world to the conference, held in cooperation with the Association for Computing Machinery's Special Interest Group in Computer-Human Interaction (ACM SIGCHI), the Association for the Advancement of Artificial Intelligence (AAAI), and the Human Factors and Ergonomics Society (HFES). 


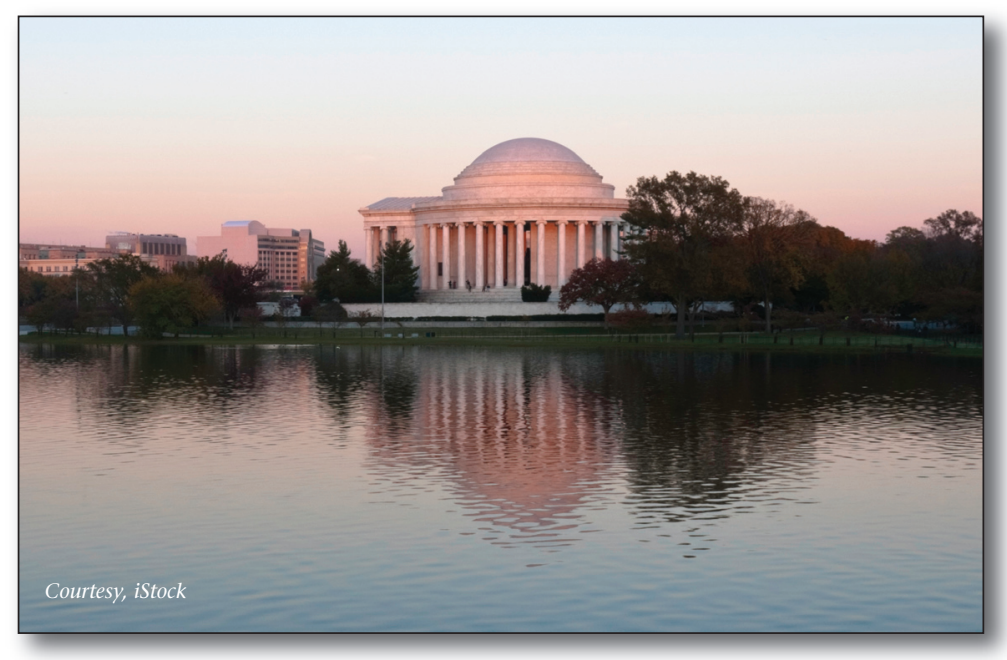

The Technology, Mind, and Society conference provided an interdisciplinary venue for reporting and assessing current efforts to understand and shape the interactions of human beings and technology, for identifying priorities for future work, and for promoting exchange and collaboration among participants. The conference was organized around four broad themes: basic research. foundations of technology design, applications, and broader implications

The theme included topics such as the ways in which humans understand and use technology, impacts of technology on human experience and behavior, human-technology interactions as mutually adaptive systems, and the role of technology in advancing other areas of scientific research. The foundations of technology design theme concerned with the development of technologies informed by psychological, behavioral, and social science research. The applications theme involved the development, use, and impact of specific technologies in domains such as aging, education, mental and physical health, recreation, and the workplace. Finally, broader implications addressed ethical, legal, and policy questions concerning the opportunities and challenges arising from human-technology interactions.

\section{Main Conference}

The two-and-a-half-day conference incorporated an impressive collection of symposia, papers, and posters, as well as keynote presentations, all focused on discoveries at the intersection of humans and technology. Four concurrent sessions across the two full days of the conference featured presentations on topics such as educational technology; cybersecurity; human-robot interactions; health, well-being, and technology; technology use and its effects across the lifespan; trust and control; technological design; and perception and cognition. There were also two poster sessions covering an even broader range of topics.

\section{Keynotes and Invited Panel}

In addition to the peer-reviewed program, the Technology, Mind, and Society conference featured four keynote presentations. Cynthia Breazeal (Massachusetts Institute of Technology) spoke on her extensive work in the creation of social robots that, through their verbal, nonverbal, and emotive expressions, meaningfully engage with people in support of their goals. Eric Horvitz (Microsoft Research) discussed his work modeling psychological processes like intention and cognition that inform the development of interactive systems that complement human intellect. Justine Cassell (Carnegie Mellon University) presented her work on verbal and nonverbal behavior that strengthens and weakens dyadic bonds, whether between humans or between humans and virtual agents. Finally, Alex "Sandy" Pentland (Massachusetts Institute of Technology) discussed his work on social physics and the ways in which big data can be used to accurately predict and shape human behavior.

The conference also included an invited panel, Human-Centered Vehicle Automation: Lessons and Questions from the Real World, with panelists Chuck Green (General Motors), Bobbie Seppelt (Massachusetts Institute of Technology), Chris Hart (National Transportation Safety Board), and David Friedman (Consumer Reports), and chair Bryan Reimer (Massachusetts Institute of Technology).

\section{Conclusion}

The conference concluded with an open discussion of the future of the field, what it needs to get there, and what role APA and other scientific organizations can play in advancing the field. The conference was chaired by Amber Story (APA), in collaboration with Tara Behrend (George Washington University), Jonathan Gratch (University of Southern California), Jeff Krichmar (University of California, Irvine), H. Chad Lane (University of Illinois, Urbana-Champaign), Bertram Malle (Brown University), Robert Proctor (Purdue University), and Diana Tamir (Princeton University).

Portions of the conference were published by the Association for Computing Machinery in their Digital Library of International Conference Proceedings Series. ${ }^{2}$

\section{Note}

1. pages.apa.org/tms

2. dl.acm.org/citation.cfm?id=3183654

Amber L. Story is the associate executive director for scientific affairs and communication at the American Psychological Association, and she served as the program chair for the Technology, Mind, and Society conference. 